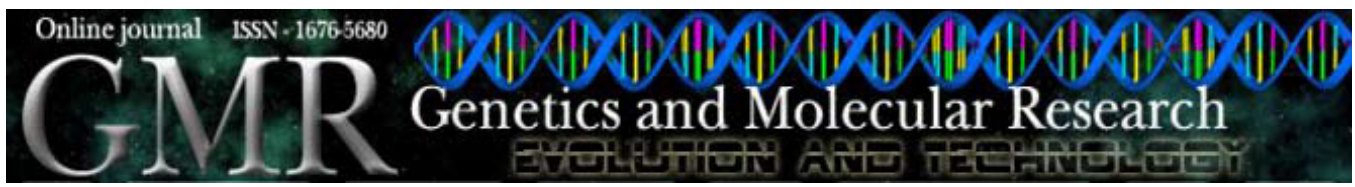

\title{
Backcross assisted by microsatellite markers in common bean
}

\author{
L.K. Oliveira ${ }^{1,3}$, L.C. Melo ${ }^{2}$, C. Brondani ${ }^{3}$, M.J.D. Peloso ${ }^{2}$ and \\ R.P.V. Brondani ${ }^{3}$ \\ 'Departamento de Biologia, Universidade Católica de Goiás, \\ Goiânia, GO, Brasil \\ ${ }^{2}$ Melhoramento de Feijão, Embrapa Arroz e Feijão, \\ Santo Antônio de Goiás, GO, Brasil \\ ${ }^{3}$ Genética Molecular, Embrapa Arroz e Feijão, \\ Santo Antônio de Goiás, GO, Brasil \\ Corresponding author: R.P.V. Brondani \\ E-mail: rosanavb@cnpaf.embrapa.br
}

Genet. Mol. Res. 7 (4): 1000-1010 (2008)

Received June 5, 2008

Accepted July 1, 2008

Published October 7, 2008

\begin{abstract}
The objectives of the present study were to monitor the effect of backcrossing through microsatellite markers and to compare different marker assisted selection strategies. Four populations were developed using donor parents resistant to the bean golden mosaic virus and, for all crosses, only individuals resistant to the bean golden mosaic virus were backcrossed. For crosses ARC100-4 x DOR303 and ARC1004 x PHAS8328, assisted selection was carried out in the $\mathrm{F}_{2}$ and $\mathrm{F}_{2} \mathrm{BC}_{1}$ generations, while in the remaining crosses selection was performed only in the $\mathrm{F}_{2} \mathrm{BC}_{1}$ generation. For the microsatellite analysis, in each generation, 20 markers were genotyped. The molecular data were analyzed using the NTSys program and the proportion of the recurrent genome introgressed was estimated, based on genotypical configuration of the segregant populations compared to the recurrent parents. The results indicate a higher efficiency in recovering the genotype of the elite genitor through the strategy of backcross assisted selection in the successive generations, and demonstrate a practical and useful application of molecular marker
\end{abstract}


technology associated with bean breeding, to reduce the number of backcrosses and the time to recover the genome of the recurrent genitors.

Key words: Assisted backcross; Molecular markers; Genetic breeding; Phaseolus vulgaris

\section{INTRODUCTION}

The concomitant use of molecular markers and phenotypic evaluation in backcross programs is considered to be a practical application of the technology of molecular markers in the scope of genetic improvement and has been shown to be effective in accelerating and reducing the number of generations needed for exotic target gene introgression (Tanksley et al., 1981; Ferreira and Grattapaglia, 1995). The use of molecular tools is becoming more effective where the phenotype of a desired trait cannot be directly assessed, making possible the direct monitoring of the genomic region that will receive the introgressed genomic segment containing the target gene. In the common bean, some studies have demonstrated the use of molecular markers co-segregating with the resistance genes and being used as a guide to target genomic regions of interest in the backcross process for rust, anthracnose (Faleiro et al., 2001) and golden mosaic resistance (Miklas, 2002). Polymerase chain reaction-based random amplified polymorphic DNA markers tightly linked to the resistance genes (R) have been used for the development of bean lines with multiple disease resistance through the selection, in successive backcross generations, of the individuals in the progeny that possess a marker allele from the donor parent and a low proportion of the remaining undesirable genome, improving the efficiency and incorporating the resistance genes into elite bean genotypes (Oliveira et al., 2005; Costa et al., 2006).

The bean golden mosaic virus (BGMV) is a serious disease that occurs within the main areas of common bean plantations in Brazil and, depending on weather conditions and on the stage of the plant development, it may cause severe yield loss that can reach $100 \%$ of grain productivity, removing from the crop system around 200.000 hectares with the potential to be cultivated with common beans (Faria and Zimmermann, 1988). Regarding the genetic control of the resistance to BGMV, there is no consensus within the scientific community, with information existing in the literature suggesting that the resistance to BGMV is under polygenic control (Pessoni et al., 1997), monogenic control (Blair and Beaver, 1993) and oligogenic control (Blair et al., 1993; Melo et al., 2005).

The assisted backcrossing process may be lead with the exclusive objective of monitoring the degree of similarity of the resistant lines to the recurrent parent, predicting the degree of kinship among the backcrossed plants. This may be done through the analysis of genetic similarity among the individuals from the progeny and the recurrent parents, as demonstrated by Hagiwara et al. (2001) using random amplified polymorphic DNA markers. In this situation, the number of backcrosses can be reduced by recovering the plants most similar to the recurrent parent, in addition to phenotypic selection for the desired trait. AlzateMarim et al. (1999) showed the usefulness of the analysis of genetic similarity in identifying individuals with a high proportion of desired genome from the recurrent parent in association with the selection for the target genomic region and obtaining, in three generation of backcrosses, recovered lines with desired genes also close to the recurrent parent.

The objectives of the present study were 1) to monitor the effect of backcrossing 
through microsatellite markers, estimating the genetic similarity with the recurrent parent in four segregating populations, aiming to increase the efficiency of the common bean improvement, and 2) to compare different selection strategies, considering the marker assisted backcross in early and advanced generations, with the aim of increasing efficiency in recovering individuals more similar to the recurrent parents.

\section{MATERIAL AND METHODS}

\section{Populations}

At Embrapa Arroz e Feijão, four populations from crosses among cultivars and lines of common bean were obtained, always using as donor parent a source of resistance to the BGMV, previously identified, and as recurrent parent a susceptible genotype with desired commercial traits. The crosses were performed among the following parents: 1) line ARC100-4 (Carioca commercial grain, Mesoamerican origin) and line DOR303 (source of resistance to BGMV with non-commercial grain, Mesoamerican origin); 2) line ARC100-4 and PHAS8328 (wild bean and source of resistance to BGMV, Mesoamerican origin); 3) line ARC100-4 and line G23554 (wild bean and source of resistance to BGMV, Mesoamerican origin), and 4) cultivar Jalo Precoce (Jalo commercial grain, Andine origin) and line G23554. These populations were conducted through the backcrossing method, followed by selfing. For all crosses in the generations $\mathrm{F}_{2}$ and $\mathrm{F}_{2} \mathrm{BC}_{1}$, only resistant plants against the BGMV were selected. Approximately 400 plants resulting from each crossing were submitted to infestation with BGMV through inoculation of the viruliferous white fly in the stage of recently emerged plants ( 50 to 80 white fly/plant in $48 \mathrm{~h}$ ). Periodic assessments were made, regarding symptom expression incidence, to define the reactions of the plants to the BGMV starting in the V3 phenological stage, when the plants had two trifoliate leaves, and ending in the R5 stage, during the formation of the floral buds. Molecular analysis of the resistant plants, that was variable in each generation, was performed on $\mathrm{F}_{2}$ and $\mathrm{F}_{2} \mathrm{BC}_{1}$ generations for crosses 1 and 2, and only on generation $\mathrm{F}_{2} \mathrm{BC}_{1}$ for the crosses 3 and 4 . The number of plants genotyped for each of the crosses was variable as a function of the resistant plants obtained.

\section{DNA extraction and microsatellite analysis}

Genomic DNA was obtained from leaf tissue samples using the protocol described by Grattapaglia et al. (1992). A set of 98 microsatellites developed for common bean and made available in the literature, as described in Table 1 (Gaitán-Solís et al., 2002; Yaish and Pérez De La Vega, 2003; Buso et al., 2006), were screened for the presence of polymorphism among the parents of the four crosses. The polymerase chain reaction and amplification conditions were conducted according to Brondani et al. (2002). Polymorphism analysis of the amplified products was carried out on $6 \%$ polyacrylamide denaturant gel stained with silver nitrate, according to Creste et al. (2001). The amplified alleles for each locus were genotyped as binary data, considering presence and absence, and organized in a matrix for statistical analysis.

\section{Statistical analysis}

The genetic similarity analysis was estimated using the distance coefficient of Jac- 
card. The unweighted pair group method using arithmetic averages (Rohlf, 1989), cluster analysis based on similarity matrices, were performed and the relationships between the progenies for each generation of crosses were visualized as dendrograms. The significance of the cophenetic correlation among the matrices obtained of genetic similarities and the matrix of cophenetic values were computed through analysis with the NTSys software (Rohlf, 1989). The stability of the grouping was tested by the re-sampling procedure with 10,000 bootstraps using the Dbood software (Coelho, 2001).

The proportion of the recurrent genome introgressed in the individuals of the $F_{2}$ and $\mathrm{F}_{2} \mathrm{BC}_{1}$ generations was determined by the total number of alleles from the recurrent parent identified in each individual of the segregating generations, including the genotypes in homozygosis and heterozygosis for the assessed simple sequence repeat (SSR) loci. The statistical chi-squared $\left(\chi^{2}\right)$ test, considering $\mathrm{P}<0.05$, was performed to test for the efficiency of the marker assisted selection procedure in order to recover the proportions of the introgressed genome in the different populations and segregating generations of backcrossing.

\section{RESULTS AND DISCUSSION}

The assessment of the $F_{1}$ generation of the four crosses studied showed that all plants were susceptible to BGMV, indicating, preliminarily, that the resistance to the disease is ruled by the recessive alleles of one or more genes.

Among the SSR markers tested, as expected, all them amplified in the four parents used in the crossings, since the transferability within Phaseolus vulgaris species has been shown to be high by Grisi (2006) and Blair et al. (2006). A selected set of 98 SSR markers, most of them mapped and distributed in eleven chromosomes of the bean (Freyre et al., 1998; Grisi, 2006), were screened for polymorphism, and 51 were found to be polymorphic in, at least, one of the four crossings tested (Table 1), ensuring a good genomic sampling. Regarding the polymorphism index, of the 51 microsatellite markers that showed to be polymorphic, 13 were common to two crosses and nine were common to three crosses.

For each cross, 20 polymorphic markers, among the parents, were selected. However, the number of tested markers in order to identify at least 20 microsatellites was higher and variable, considering the level of variability among the parental combinations represented in this study. For the crosses ARC100-4 x DOR303, ARC100-4 x PHAS8328, ARC100-4 x G23554, and Jalo Precoce x G23554, there were assessed 48, 50, 96, and 48 microsatellite markers, respectively, with the estimated level of polymorphism higher in the crossing Jalo Precoce $\mathrm{x}$ G23554 (52\%), and lower in the crossing ARC100-4 x G23554 (20.8\%). The polymorphism detected between the parental combinations evaluated in this study agrees with previous reports where polymorphism is low among crosses involving parentals from the same gene pool and higher for crosses between gene pools, as described by Grisi (2006) and Blair et al. (2006), due to the limited genetic diversity in P. vulgaris. They found an average level of polymorphism that ranged from 54 to $77 \%$ for inter-gene pool, respectively, and an index generally lower than $35 \%$ within the gene pool. Reductions in genetic diversity have been reported in the genus Phaseolus, as a consequence of events that occurred during the initial domestication process, followed by the dissemination of cultivated beans from their domestication centers, and the selection implemented in plant breeding programs to incorporate desired traits (Papa et al., 2005). Despite the plant morphological variations, that allowed every parental used in this study to be 
Table 1. Description of a set of 51 Phaseolus vulgaris microsatellite markers used for molecular analysis of the four segregant populations.

\begin{tabular}{|c|c|c|c|}
\hline Microsatellites & A.T. $\left({ }^{\circ} \mathrm{C}\right)$ & L.G. & $\begin{array}{c}\text { Polymorphic } \\
\text { populations }\end{array}$ \\
\hline BM68 & 56 & 4 & 4 \\
\hline BM98 & 56 & 3 & 4 \\
\hline BM114 & 56 & 9 & $2 / 4$ \\
\hline BM137 & 56 & 6 & 3 \\
\hline BM138 & 56 & 5 & 2 \\
\hline BM140 & 56 & 4 & 4 \\
\hline BM142 & 56 & 2 & 2 \\
\hline BM143 & 56 & n.m. & 1 \\
\hline BM148 & 56 & n.m. & $2 / 3$ \\
\hline BM149 & 56 & 4 & 1 \\
\hline BM151 & 56 & n.m. & $2 / 4$ \\
\hline BM152 & 56 & 2 & 1 \\
\hline BM153 & 56 & n.m. & 4 \\
\hline BM154 & 56 & 9 & $1 / 3$ \\
\hline BM155 & 56 & 5 & $1 / 2 / 3$ \\
\hline AJ416394 & 56 & n.m. & 2 \\
\hline GATS11 & 56 & n.m. & $2 / 3 / 4$ \\
\hline GATS91 & 56 & 2 & $1 / 2 / 4$ \\
\hline PV05 & 56 & 6 & $1 / 2 / 4$ \\
\hline PV11 & 56 & 2 & $4 / 3$ \\
\hline PV12 & 56 & 10 & 1 \\
\hline PV13 & 56 & 6 & $1 / 4$ \\
\hline BM156 & 56 & 2 & 1 \\
\hline BM158 & 56 & n.m. & 3 \\
\hline BM159 & 56 & 3 & 3 \\
\hline BM160 & 56 & 7 & $1 / 3 / 4$ \\
\hline BM161 & 56 & $8 / 4$ & 2 \\
\hline BM164 & 56 & 2 & 1 \\
\hline BM165 & 56 & 8 & 4 \\
\hline BM175 & 56 & 5 & $1 / 2$ \\
\hline BM183 & 56 & 7 & 2 \\
\hline BM184 & 56 & $11 / 9$ & 2 \\
\hline BM200 & 56 & 1 & 1 \\
\hline BM202 & 56 & 9 & 1 \\
\hline BM210 & 56 & 7 & 1 \\
\hline BM211 & 56 & 8 & 2 \\
\hline BM212 & 56 & 10 & $1 / 3$ \\
\hline BM213 & 56 & n.m. & $2 / 4$ \\
\hline PV21 & 56 & 3 & $2 / 3 / 4$ \\
\hline PV23 & 56 & 3 & $2 / 3 / 4$ \\
\hline PV25 & 56 & 2 & 1 \\
\hline PV34 & 56 & n.m. & 3 \\
\hline PV53 & 56 & 8 & $3 / 4$ \\
\hline PV61 & 56 & 5 & 3 \\
\hline PV67 & 56 & n.m. & $1 / 2 / 3$ \\
\hline PV77 & 56 & n.m. & $1 / 2 / 3$ \\
\hline PV78 & 56 & 2 & $3 / 4$ \\
\hline PV81 & 56 & n.m. & 4 \\
\hline PV93 & 56 & 5 & $3 / 4$ \\
\hline PV101 & 56 & 9 & 4 \\
\hline PV109 & 56 & 3 & $3 / 4$ \\
\hline
\end{tabular}

Annealing temperature (A.T.), linkage group position (L.G.) and polymorphic populations are specified for each loci. n.m. $=$ not mapped. 
easily distinguished, microsatellite marker polymorphism was not easily detected among them. The reasons for that is the fact that the molecular markers are in most cases phenotypically neutral, abundant in the genome and environmentally independent, ensuring a good representation of the whole genome and less vulnerability to the selection imposed by man (Gepts, 2002).

The markers initially identified as polymorphic among the parents of the crosses ARC100-4 x DOR303 and ARC100-4 x PHAS8328 were used to genotype the $\mathrm{F}_{2}$ plants identified as resistant to BGMV. The matrix derived from the microsatellite was constructed with binary data (presence or absence of SSR bands), to obtain estimates of the genetic similarity between the $\mathrm{F}_{2}$ plants, aiming to identify the individuals more similar to the recurrent parent, ARC100-4, as presented in Table 2 . The 10 resistant $\mathrm{F}_{2}$ plants that showed to be genetically closer to the recurrent parent were backcrossed to the recurrent parent. The $\mathrm{F}_{1} \mathrm{BC}_{2}$ plants were selfed to obtain $\mathrm{F}_{2} \mathrm{BC}_{1}$ plants. The $\mathrm{F}_{2} \mathrm{BC}_{1}$ population was submitted to a phenotypic analysis for $\mathrm{BGMV}$ resistance, and the selected plants were genotyped using the microsatellite markers previously identified as polymorphic between the parents of each cross. The genetic diversity estimated among the $\mathrm{F}_{2} \mathrm{BC}_{1}$ populations in relation to their parents was used to select the 10 most genetically similar individuals compared to the recurrent parents for a new round of backcrossing.

For the crosses involving the parentals ARC100-4 x G23554 and Jalo Precoce x G23554, which the genitor $\mathrm{G} 23554$ participated as the wild donor parent, all $\mathrm{F}_{1}$ plants obtained were backcrossed to the elite parent. The resulting $\mathrm{F}_{2} \mathrm{BC}_{1}$ individuals were phenotyped for the reaction to BGMV and the resistant ones were submitted to molecular analysis in order to identify the ones more genetically similar to the recurrent parent, to be used in the next generation of backcrosses.

The genetic similarity estimated for the $\mathrm{F}_{2} \mathrm{BC}_{1}$ resistant individuals of crosses 1 and 2 (with backcross assisted selection in the $\mathrm{F}_{2}$ generation), and crosses 3 and 4 (without the selection in $\mathrm{F}_{1}$ ), when compared with the recurrent parents (Table 2), showed to be higher when the selection assisted by microsatellite markers was performed in the early generation $(0.82$ and 0.65 , for monitored crosses in both $\mathrm{F}_{2}$ and $\mathrm{F}_{2} \mathrm{BC}_{1}$ generations, and 0.38 and 0.52 for the monitored crosses only in $\mathrm{F}_{2} \mathrm{BC}_{1}$ generation). Keeping the number of microsatellite markers used for monitoring the individuals in $\mathrm{F}_{2}$ and $\mathrm{F}_{2} \mathrm{BC}_{1}$ generations constant and changing the population size as a function of the total number of plants resistant, the results obtained showed, in a practical way, the efficiency of marker-assisted selection mainly on early generations, leading to the release of plants with the desired resistance to the BGMV and genetically closer to the recurrent parent, reducing the number of backcrosses needed for the complete inbred line conversion.

The proportion of the recurrent genotype detected in the individuals of $\mathrm{F}_{2}$ generation (Table 2) ranged from 69.4 to $16.6 \%$ and from 71.8 to $25 \%$, with an average of 41.9 and $47.5 \%$ for the populations ARC100-4 x DOR303 and ARC100-4 x PHAS8328, respectively (Figure 1 ). These results are very close to those expected for $\mathrm{F}_{2}$ generation (on average, $50 \%$ of the alleles of each genitor), despite this, for the cross ARC100-4 x DOR303, the proportion was statistically different from that expected using the $\chi^{2}$ test at $\mathrm{P}<0.05$. However, as pointed out, the plants submitted to the molecular analysis were previously selected for resistance to the BGMV and several individuals were discarded. This selection probably resulted in a lower representation of the recurrent parent alleles, deviating from the expected proportion.

The proportion of the recurrent parent genome was also calculated in the $\mathrm{F}_{2} \mathrm{BC}_{1}$ generation. For the cross ARC100-4 x DOR303, the average proportion of ARC100-4 was $88.3 \%$ (varying from 72.2 to $100 \%$ ), deviating significantly from the expected value $(75 \%)$. Considering the cross ARC100-4 x PHAS8328, the average proportion of ARC100-4 was 76.7\% (ranging from 55.5 to 
L.K. Oliveira et al.

1006

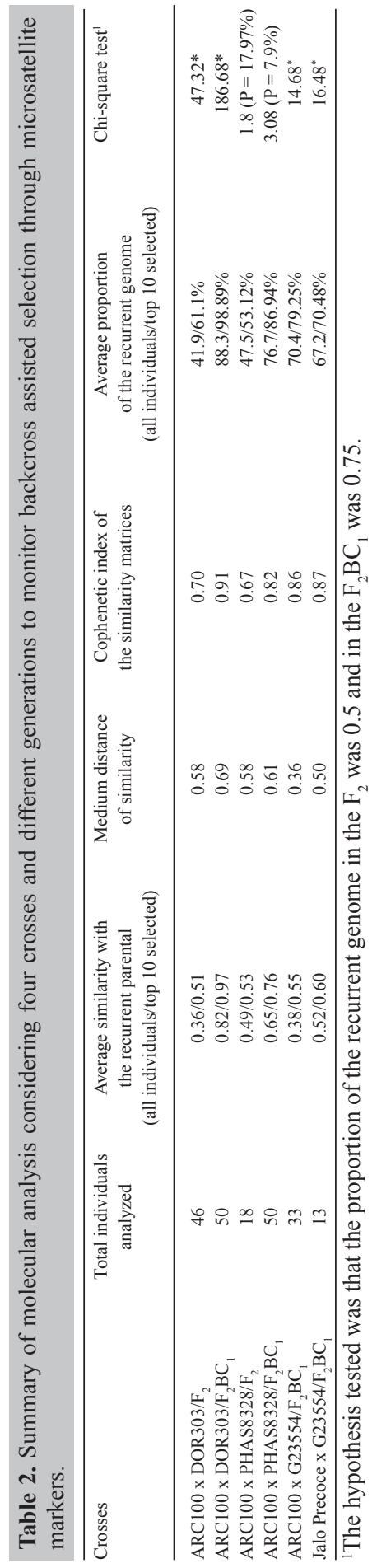

Genetics and Molecular Research 7 (4): 1000-1010 (2008) 

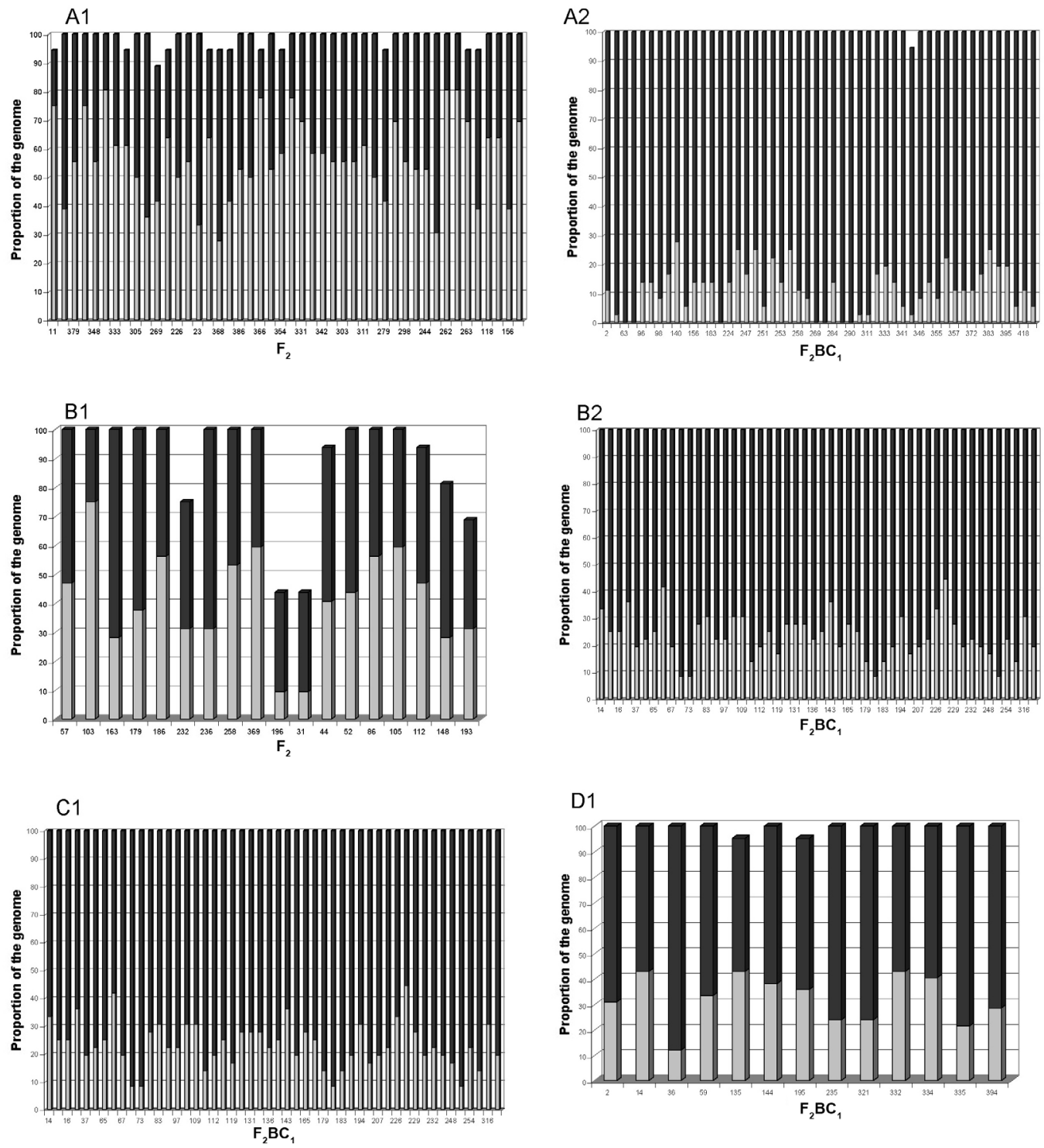

Figure 1. Proportion of the recurrent parent genome incorporated into the $\mathrm{F}_{2}$ individuals for crossings 1 and 2 (graphics $\mathrm{A} 1$ and $\mathrm{B} 1$, respectively), and $\mathrm{F}_{2} \mathrm{BC}_{1}$ individuals for crossings 1, 2, 3, and 4 (graphics A2, B2, $\mathrm{C} 1$, and D1, respectively). The grey portion and dark portion of the bar are related to the genome proportion of the donor parent and the recurrent parent, respectively. Bars that do not reach $100 \%$ refer to missed data.

91.6\%), which did not differ from the expected value (Figure 1). In the analysis in the $\mathrm{F}_{2} \mathrm{BC}_{1}$ generation, which was conducted without backcross assisted selection, the proportion of the recurrent genome estimated showed to be more variable, with some individuals genetically more similar to the donor parent. For the cross ARC100-4 x G23554, the average proportion of ARC100-4 was 70.4\% 
(ranging from 47.5 to $92.5 \%$ ). For the cross Jalo Precoce x G23554, the average proportion of Jalo Precoce was $67.2 \%$ (ranging from 52.3 to $88 \%$ ). These two crosses showed a lower deviation from the expected value. Despite the fact that, for some plants the recovered alleles of the recurrent parent fitted the expected value of $75 \%$, most of the plants had a value that was lower than expected, indicating that many plants still presented high proportions of the donor parent.

Among the genetic similarity to the recurrent parent estimated in the $\mathrm{F}_{2} \mathrm{BC}_{1}$ generation for the crosses 1 and 2, where the backcross assisted selection was performed in the $\mathrm{F}_{2}$ generation, and for the crosses 3 and 4, with the marker assisted selection performed only in the advanced generation, the percentage of plants that recovered the alleles of the recurrent parent was numerically higher $(\mathrm{P}<0.05)$, when the assisted selection was performed in the early generation (proportion of 88.3 and $76.7 \%$ for the crosses 1 and 2, respectively, and 70.4 and $67.2 \%$ for the crosses 3 and 4, respectively) (Table 2). Based on the results obtained for the sampled loci in the genome, compared to the expected proportion and considering the breeding cross strategies employed in the present study, the use of microsatellite markers to predict the degree of genetic similarity among the generations of backcrosses showed to be very efficient, practical and that it should be implemented as routine in the common bean breeding program.

Once the effects of the assisted selection could be assessed in the next generation, only in the $\mathrm{F}_{2} \mathrm{BC}_{1}$ generation of the crosses 1 and 2, where the $\mathrm{F}_{2}$ individuals were submitted to the microsatellite marker selection, it was possible to assess the effect of the selection based on the levels of genetic similarity, which was useful in estimating the proportion of the recurrent parent genome recovered. As the selection in the $\mathrm{F}_{2}$ generation indicated for backcross only the individuals genetically more similar to the recurrent parent, a deviation towards the proportion of the introgressed recurrent genome above that expected in the $\mathrm{F}_{2} \mathrm{BC}_{1}$ generation was naturally expected, as was observed. For cross 1 , the selection based on microsatellite markers in the $\mathrm{F}_{2}$ generation showed to be very effective, with a medium similarity of $88.3 \%$, statistically different from the expected value of 75 at $5 \%$ of probability (Table 2 ). For cross 2 , despite the average similarity value being higher than expected, the difference was not significant.

Regarding the crosses 1 and 2, the average similarity of the progeny with the recurrent parent was $82.5 \%$, while for crosses 3 and 4 the mean value of similarity was $68 \%$; the differences between the early selection using microsatellite markers and the conventional process of backcross are statistically significant and, in a practical way, show an increase of $14.5 \%$ in the efficiency of recurrent parent genome recovery in one generation of monitored assisted backcross.

These results are in accordance with previously studies of the common bean where molecular markers were used as a complementary strategy to phenotypic analysis in order to improve and accelerate the process of backcross in breeding programs (Hagiwara et al., 2001). This indicates the efficiency of backcross assisted selection in the early generation of crosses through analysis of genetic similarity with the recurrent parent and can be implemented as routine in the common bean breeding program.

As the set of microsatellite markers used for the genetic analysis was not the same for all crosses, due to the different abilities of the markers to detect polymorphism between the different combinations of genitors, determined groups of markers used could be more efficient in order to sample donor introgressions. Certainly, the use of more microsatellite markers, with a better coverage of the chromosomes, and the strategy that 
increases the number of individuals with the advance of backcrosses, would bring more accuracy to the analysis, and consequently, an increase in the efficiency of the backcross assisted selection, as suggested by Frisch and Melchinger (2001) and Hospital and Charcosset (1997). In a simulation study, the use of six microsatellite markers per chromosome in maize showed to be efficient in transferring, at both molecular and phenotypic level, the target allele from the donor to the desired genotype, resulting in plants that were closer to the recurrent parent and, consequently, increasing the efficiency of a backcross marker assisted strategy (Benchimol et al., 2005).

\section{CONCLUSIONS}

The use of backcross assisted selection is efficient in the recovery process of the recurrent parent genome, contributing to an accelerated process.

Backcross assisted selection in early generations increases recovery of the recurrent parent genome and can reduce additional backcrossing, reducing time and cost in the breeding program.

\section{ACKNOWLEDGMENTS}

Research supported by the Brazilian agency Conselho Nacional de Desenvolvimento Científico e Tecnológico (CNPq).

\section{REFERENCES}

Alzate-Marin AL, Arruda MCC, Menarim H, Chagas JM, et al. (1999). Identification of RAPD markers linked to resistance genes to anthracnose in common bean cultivars AB136, TO and G2333. Annu. Rep. Bean Improv. Cooperative 42: 13-14.

Benchimol LL, de Souza CL Jr and de Souza AP (2005). Microsatellite-assisted backcross selection in maize. Genet. Mol. Biol. 28: 789-797.

Blair MV and Beaver JC (1993). Inheritance of bean golden mosaic virus resistance from bean genotype A429. Annu. Rep. Bean Improv. Cooperative 36: 143.

Blair MV, Beaver JC and Adames C (1993). Inheritance of the dwarfing response to bean golden mosaic virus infection in dry beans (Phaseolus vulgaris). Annu. Rep. Bean Improv. Cooperative 36: 144-145.

Blair MW, Giraldo MC, Buendia HF, Tovar E, et al. (2006). Microsatellite marker diversity in common bean (Phaseolus vulgaris L.). Theor. Appl. Genet. 113: 100-109.

Brondani RP, Brondani C and Grattapaglia D (2002). Towards a genus-wide reference linkage map for Eucalyptus based exclusively on highly informative microsatellite markers. Mol. Genet. Genomics 267: 338-347.

Buso GSC, Amaral ZPS, Brondani RPV and Ferreira ME (2006). Microsatellite markers for the common bean Phaseolus vulgaris. Mol. Ecol. Notes 6: 252-254.

Coelho ASG (2001). DBOOT: Avaliação dos erros associados a estimativas de distâncias/similaridades genéticas através do procedimento de bootstrap com número variável de marcadores. Versão 1.1. Universidade Federal de Goiás, Goiânia.

Costa MR, Tanure JPM, Arruda KMA, Carneiro JES, et al. (2006). Pyramiding of anthracnose, angular leaf spot and rust resistance genes in black and red bean cultivars. Annu. Rep. Bean Improv. Cooperative 49: 187-188.

Creste S, Tulmann-Neto A and Figueira A (2001). Detection of single sequence repeat polymorphisms in denaturing polyacrylamide sequencing gels by silver staining. Plant Mol. Biol. Rep. 19: 299-306.

Faleiro FG, Ragagnin VA, Carvalho GA, Paula TJ Jr, et al. (2001). Development of common bean lines resistant to rust and anthracnose by molecular marker-assisted backcrossing. Annu. Rep. Bean Improv. Cooperative 44: 109-110.

Faria JC and Zimmermann MJO (1988). Controle do mosaico dourado do feijoeiro (Phaseolus vulgaris) pela resistência varietal e inseticidas. Fitopatol. Bras. 13: 32-35.

Ferreira ME and Grattapaglia D (1998). Introdução ao Uso de Marcadores Moleculares em Análise Genética. EMBRAPA, Brasília. 
Freyre R, Skroch PW, Geffroy V, Adam-Blondon AF, et al. (1998). Towards an integrated linkage map of common bean. Development of a core linkage map and alignment of RFLP maps. Theor. Appl. Genet. 97: 847-856.

Frisch M and Melchinger AE (2001). Marker-assisted backcrossing for introgression of a recessive gene. Crop Sci. 41: 1485-1494.

Gaitán-Solís E, Duque MC, Edwards KJ and Tohme J (2002). Microsatellite repeats in common bean (Phaseolus vulgaris): Isolation, characterization, and cross-species amplification in Phaseolus ssp. Crop Sci. 42: 2128-2136.

Gepts P (2002). A comparison between crop domestication, classical plant breeding, and genetic engineering. Crop Sci. 42: $1780-1790$.

Grattapaglia D, O'Malley D and Sederoff RR (1992). Multiple applications of RAPD markers to genetic analysis of Eucalyptus sp. In: Proceedings of IUFRO International Conference "Breeding tropical trees", Cali, 436-450.

Grisi MCM (2006). Mapeamento genético de locos microssatélites em feijoeiro comum utilizando a população Bat93 x Jalo EEP558. Master's thesis, Universidade Federal de Goiás, Goiânia.

Hagiwara WE, dos Santos JB and do Carmo SLM (2001). Use of RAPD to aid selection in common bean backcross breeding programs. Crop Breed. Appl. Biotechnol. 1: 355-362.

Hospital F and Charcosset A (1997). Marker-assisted introgression of quantitative trait loci. Genetics 147: 1469-1485.

Melo LC, Farias JC, Rosária L, Yokoyama M, et al. (2005). Controle genético da reação do feijoeiro comum ao vírus do mosaico dourado. In: Anais do Congresso Nacional de Pesquisa de Feijão - CONAFE. Embrapa Arroz e Feijão, Santo Antônio de Goiás, 393-396.

Miklas PN (2002). Marker-assisted selection for disease resistance in common beans. Annu. Rep. Bean Improv. Cooperative 45: $1-3$.

Oliveira EJ, Alzate-Marin AL, Borem A, de Azeredo FS, et al. (2005). Molecular marker-assisted selection for development of common bean lines resistant to angular leaf spot. Plant Breed. 124: 572-575.

Papa R, Acosta J, Delgado-Salinas A and Gepts P (2005). A genome-wide analysis of differentiation between wild and domesticated Phaseolus vulgaris from Mesoamerica. Theor. Appl. Genet. 111: 1147-1158.

Pessoni LA, Zimmermann MJD and de Faria JC (1997). Genetic control of characters associated with bean golden mosaic geminivirus resistance in Phaseolus vulgaris L. Braz. J. Genet. 20: 51-58.

Rohlf FJ (1989). NTSYS-Pc: Numerical Taxonomy and Multivariate Analysis System. Exeter Publishers, New York.

Tanksley SD, Medina-Filho H and Rick H (1981). The effect of isozyme selection on metric characters in an interspecific backcross of tomato - basis of an early screening procedure. Theor. Appl. Genet. 60: 291-296.

Yaish MWF and Pérez De La Vega M (2003). Isolation of (GA)n microsatellite sequences and description of a predicted MADS-box sequence isolated from common bean (Phaseolus vulgaris L.). Genet. Mol. Biol. 26: 337-342. 